\title{
Investigation of hematological parameters related to the severity of COVID-19 disease in Mashhad, Iran
}

\author{
Mohsen Seddigh-Shamsi ${ }^{\circledR}$, Shima Nabavi Mahali ${ }^{\circledR}{ }^{\circledR}$, Mahnaz Mozdourian $^{3}{ }^{\circledR}$, Abolghasem Allahyari $^{\circledR}$, Neda Saeedian $^{2^{\circledR}}$, Maryam $^{\circ}$

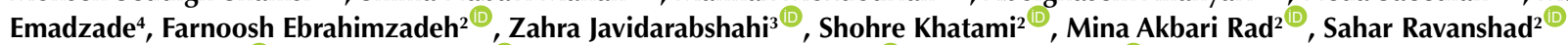 \\ , Maryam Naghavi ${ }^{\circledR}$, Zahra Mozaheb ${ }^{1}$, Mohammad Moeini Nodeh ${ }^{\circledR}$, Hossein Rahimi ${ }^{\circledR}$, Alireza Bary ${ }^{1}$, Mostafa Kamandi $^{\circledR}$, \\ Sajad Ataei Azimi ${ }^{\circledR}$, Mohammad Ali Yaghoubi ${ }^{(\mathbb{}}{ }^{\circledR}$, Zahra Rezaei Borojerdi ${ }^{* *}$ \\ 'Department of Hematology Oncology, Faculty of Medicine, Mashhad University of Medical Sciences, Mashhad, Iran \\ ${ }^{2}$ Department of Internal Medicine, Faculty of Medicine, Mashhad University of Medical Sciences, Mashhad, Iran \\ ${ }^{3}$ Lung Disease Research Center, Mashhad University of Medical Sciences, Mashhad, Iran \\ ${ }^{4}$ Clinical Research Development Unit, Ghaem Hospital, Mashhad University of Medical Sciences, Mashhad, Iran \\ ${ }^{5}$ Internal Medicine Resident, Internal Medicine Department, Imam Reza Hospital, Mashhad University of Medical sciences, Mashhad, Iran \\ ${ }^{6}$ Metabolic Syndrome Research Center, Faculty of Medicine, Mashhad University of Medical Sciences, Mashhad, Iran
}

\section{*Correspondence to}

Zahra Rezaei Borojerdi, Email: Drzr358@gmail.com, Rezaeibz961@mums.ac.ir

Received 17 Sep. 2020 Accepted 5 Oct. 2020 Published online 18 Oct. 2020

Keywords: COVID-19, Hematological parameters, Pneumonia, Severe acute respiratory syndrome coronavirus, Acute respiratory distress syndrome

Citation: SeddighShamsi M, Nabavi Mahali S, Mozdourian $\mathrm{M}$, Allahyari A Saeedian N, Emadzade $\mathrm{M}$, Ebrahimzadeh F, Javidarabshahi J, Khatami S, Akbari Rad M, Ravanshad S, Naghavi M, Mozaheb Z, Moeini Nodeh M, Rahimi H, Kamandi M, Ataei Azimi S, Yaghoubi MA, Rezaei Borojerdi Z. Investigation of hematological parameters related to the severity of COVID-19 disease in Mashhad, Iran. Immunopathol Persa. 2021;7(2):e19. DOI:10.34172/ ipp.2021.19.

\section{Abstract}

Introduction: Human coronavirus disease 2019 (COVID-19) is an emerging respiratory disease that has become pandemic worldwide. The patients have a range of mild to severe symptoms, such as pneumonia, acute respiratory distress syndrome, arrhythmia, shock, and other organs involvement. Clinical and hematological evidence can serve as a prognostic factor to detect severe cases of COVID-19.

Objectives: The present study aimed to evaluate hematological parameters related to the severity of the disease in COVID-19 patients in Mashhad, Eastern Iran.

Patients and Methods: All the individuals with positive real-time reverse transcription-polymerase chain reaction test results and the patients with clinical symptoms whose computed tomography scan results were matched with the diagnosis of viral pneumonia were included in the study. The hematological examinations and complete blood count of the patients were performed by the healthcare personnel through collecting blood samples at the time of admission and discharge from the hospital.

Results: In total, 189 COVID-19 patients were included in the study, $47.6 \%$ and $58.73 \%$ of whom were over 60 years old and male, respectively. Investigation of the hematological parameters revealed that the number of white blood cells, mean value of corpuscular volume, number of platelets, and lymph count had significantly increased at the time of discharge $(P<0.01)$. On the other hand, red blood cells, hemoglobin, hematocrit, mean corpuscular hemoglobin, mean corpuscular hemoglobin, and red cell distribution width values were significantly higher at the time of admission in comparison to discharge $(P<0.01)$. Furthermore, it was found that male gender had a significant relationship with the development of lymphopenia in the patients $(P=0.021)$.

Conclusion: It can be concluded that hematological parameters and inflammatory biomarkers in COVID-19 patients could potentially act as the independent factors and affect the prognosis of the disease.

\section{Introduction}

Over the last two decades, the emergence of diseases, such as severe acute respiratory syndrome coronavirus (SARS-CoV) with over $10 \%$ and Middle East respiratory syndrome coronavirus with $37 \%$ mortality rates, infected more than 10000 people worldwide and were considered public health challenges (1-6). Coronaviruses are enveloped singlestranded RNA viruses with an animal origin that belong to the Coronaviridae family and Nidovirales order. They are commonly found in human and animal populations as well as

\begin{abstract}
Key point
COVID-19 is an emerging respiratory disease that has become pandemic worldwide. In this study, hematological parameters revealed that the white blood cells count, mean value of corpuscular volume, number of platelets, and lymphocyte count had significantly increased at the time of discharge. On the other hand, red blood cells, hemoglobin, hematocrit, mean corpuscular hemoglobin, mean corpuscular hemoglobin, and red cell distribution width values were significantly higher at the time of admission in comparison to the time of discharge. We concluded that the clinical and hematological evidence can potentially act as independent factors and affect the prognosis of the disease.
\end{abstract}

Copyright $(\subset 2021$ The Author(s); Published by Nickan Research Institute. This is an open-access article distributed under the terms of the Creative Commons Attribution License (http://creativecommons.org/licenses/by/4.0), which permits unrestricted use, distribution, and reproduction in any medium, provided the original work is properly cited. 
birds, and often cause asymptomatic to mild respiratory, gastrointestinal, liver and neurological diseases $(7,8)$.

In December 2019, a new outbreak of SARS-CoV-2 was reported in Wuhan, China, called by the World Health Organization (WHO) and the Center for Disease Control and Prevention as COVID-19 (9-12). Being potentially transmitted during the incubation period, COVID-19 increased exponentially and spread to other countries, such as Thailand, South Korea, and the United States, as a pandemic (8,13-15).

The most common clinical manifestations of COVID-19 include dry cough, fever, dyspnea, myalgia, fatigue, and lymphopenia while its radiologic manifestation is pneumonia (11). In severe cases, the disease may cause acute respiratory distress syndrome (ARDS), arrhythmia, shock, secondary infections, acute heart damage, kidney failure, and even death $(9,10,15)$.

Nature of the virus and its symptoms are unknown and neither specific vaccine nor medication is available for its treatment. Therefore, it seems essential to carefully examine the patients, their symptoms, test results, and radiological findings to compare treated cases with those who died of this disease to find a strategy for the management and possibly treatment of these patients (16). However, due to the lack of evidence on the relationship between hematological parameters and the severity of COVID-19, this study aimed to investigate hematological parameters associated with the severity of the disease in patients with COVID-19 in eastern Iran.

\section{Objectives}

In this study all demographic and hematologic parameters of COVID-19 patients at the time of admission and discharge from the hospital were collected. Then, the association of these markers with the prognosis and severity of the patients has been studied.

\section{Patients and Methods}

\section{Study protocol}

The present cohort study was carried out on patients with COVID-19 who were hospitalized in the infectious diseases wards of Imam Reza hospital in Mashhad, Iran. All the patients who had positive real-time reverse transcription-polymerase chain reaction test and those with clinical symptoms whose computed tomography (CT) scan results, which were matched with the diagnosis of viral pneumonia were included in the study. However, the patients with leukemia, thalassemia, hemophilia, and other blood disorders, as well as patients undergoing chemotherapy were excluded from this research.

The demographic, clinical, and laboratory data of the subjects, as well as their other characteristics, such as olfactory disorders, smoking, and addiction, were assessed and recorded. The hematological laboratory tests and complete blood count were performed by the healthcare personnel through collecting blood samples on admission and discharge in accordance with the standards of WHO while maintaining the working conditions. According to the WHO classification, moderate COVID-19 cases were defined by clinical signs of pneumonia (fever, cough, dyspnea, fast breathing) but no signs of severe pneumonia, including $\mathrm{SpO} 2 \geq 90 \%$ on room air. On the other hand, severe form was defined with clinical signs of pneumonia (fever, cough, dyspnea, fast breathing) plus one of the following: respiratory rate $>30$ breaths/min; severe respiratory distress; or $\mathrm{SpO} 2<90 \%$ on room air.

Dexamethasone was prescribed during hospitalization of patients and this explains the increase of white blood cell (WBC) count. However, dexamethasone administration causes neutrophilia, but in our patients at the time of discharge of lymphopenia, patients improved, which confirms the value of assessing the absolute value of lymphocytes in the course of the disease. Regarding the decrease of hemoglobin $(\mathrm{Hb})$ and hematocrit (HCT), the cause can be hydration of patients and frequent blood sampling during hospitalization .In case of platelet increase, the cause may be the elimination of the suppressive effect of the virus on the bone marrow, which has improved in the course of hospitalization. Reducing red cell distribution width (RDW) during treatment is valuable and can be considered as an indicator of response to treatment.

Moreover, the discharge criteria in this study were based on the guideline of the Iranian ministry of health which consisted of lack of fever within $48-72 \mathrm{~h}$ without taking any antipyretics and $\mathrm{SpO} 2$ over $93 \%$ on room air. The clinical and laboratory data of the patients as well as their mortality rates, need for admission in the intensive care unit (ICU), lymphopenia, and antibiotic administration at the time of admission and discharge were compared as well. Principles of the ICU admission decision-making process include 1) Attention to the patient's previous condition such as; age (of particular importance for COVID patients), comorbidities (major versus stabilized, single versus multiple), neurocognitive status (normal, mildly impaired, or severely impaired cognitive functions), worsening of the patient's general condition; 2) Attention to current clinical severity with assessment of the number of organ failures at the time of decision-making such as: respiratory (hypoxemia or respiratory distress), hemodynamics (systolic blood pressure $<90 \mathrm{~mm} \mathrm{Hg}$ ), neurological (Glasgow Coma Scale $<12$ ), worsening of organ dysfunction, possible use of the SOFA score; 3) Assessment of patient's comfort such as: pain, anxiety, agitation, dyspnea, congestion, asphyxiation, and isolation; 4) A full commitment to providing support and care for all, in a way that respect the patient's dignity. These principles are not specific to COVID patients but may have greater bearing on the nature of the decision taken, depending on the situation. 


\section{Ethical issues}

The research followed the tenets of the Declaration of Helsinki. The institutional ethical committee at Mashhad University of Medical Sciences approved all study protocols (IR.MUMS.REC.1398.308). Accordingly, written informed consent was taken from all participants before any intervention.

\section{Statistical methods}

The demographic information and clinical observations were analyzed in SPSS software (version 22) using the descriptive statistical methods, including central tendency, dispersion, and frequency distribution. Furthermore, the difference between frequencies of the qualitative variables was investigated using the $\chi^{2}$ test. Besides, depending on the data distribution, the independent $t$ test or MannWhitney $U$ test were applied to compare clinical and laboratory signs with regard to the development of lymphopenia, the need for ICU hospitalization, antibiotic administration, CT scan results, and mortality. The paired $t$ test or Wilcoxon test was also used to evaluate the rate of changes in the studied indicators at the time of admission and discharge. The receiver operating curve (ROC) was also plotted to determine the area under the curve (AUC) for special values. In all the tests $P<0.05$ was considered statically significant.

\section{Results}

A total of 189 patients with COVID-19 were included in the study, $47.6 \%$ of whom were over 60 years of age and $58.7 \%$ were male. The prevalence rates of lymphopenia in the patients admitted with COVID-19 and those who were discharged were $50.3 \%$ and $40.9 \%$, respectively. Besides, the case fatality rate of this disease was $10.6 \%$. According to radiological reports, $71.4 \%$ and $28.6 \%$ of the patients had $\geq 3$ and $\leq 2$ lobes involvement, respectively. Other characteristics of the included patients are shown in Table 1.

The results of evaluation of hematological parameters of the COVID-19 patients at the time of admission and discharge showed that the number of their WBCs, mean corpuscular volume (MCV), number of platelets (PLT), and lymph counts had significantly increased at the time of discharge $(P<0.05)$. On the other hand, their $\mathrm{Hb}, \mathrm{HCT}$, mean corpuscular hemoglobin $(\mathrm{MCH})$, mean corpuscular hemoglobin concentration (MCHC), and RDW were significantly higher at the time of admission than discharge from the hospital $(P<0.05$; Table 2$)$.

As shown in Table 3, the study of the risk factors in COVID-19 patients indicated that $49.5 \%$ and $50.5 \%$ of the patients with lymphopenia were $<60$ and $\geq 60$ years old, respectively. Nevertheless, no significant difference was observed between age and lymphopenia $(P>0.05)$. Regarding gender, the results showed that $67.4 \%$ of the patients with lymphopenia were male while only $32.6 \%$
Table 1. Demographic and basic information of COVID-19 patients

\begin{tabular}{|c|c|}
\hline Variable & No. $(\%) /$ Mean $(\mathrm{SD})$ \\
\hline \multicolumn{2}{|l|}{ Age (year) } \\
\hline 60 & $99(52.4 \%)$ \\
\hline$\geq 60$ & $90(47.6 \%)$ \\
\hline Gender (male) & $111(58.73 \%)$ \\
\hline Lymphopenia upon admission & $95(50.3 \%)$ \\
\hline Lymphopenia upon discharge & $56(40.9 \%)$ \\
\hline \multicolumn{2}{|l|}{ Radiological severity of the disease } \\
\hline$\leq 2$ lobes & $54(28.6 \%)$ \\
\hline$\geq 3$ Lobes & $135(71.4 \%)$ \\
\hline \multicolumn{2}{|l|}{ Severity of the disease } \\
\hline Moderate & $32(17 \%)$ \\
\hline Severe & $156(83 \%)$ \\
\hline Death & $20(10.6 \%)$ \\
\hline Diabetes & $60(31.7 \%)$ \\
\hline Ischemic heart disease & $31(16.4 \%)$ \\
\hline Hypertension & $54(28.6 \%)$ \\
\hline Smoking & $27(14.3 \%)$ \\
\hline Need ICU admission & $13(6.9 \%)$ \\
\hline White blood cells $\left(\times 10^{3} / \mu \mathrm{L}\right)$ & $7.27 \pm 3.48$ \\
\hline Red blood cells $\left(\times 10^{6} / \mu \mathrm{L}\right)$ & $4.66 \pm 0.65$ \\
\hline Hemoglobin (g/dL) & $13.39 \pm 1.9$ \\
\hline Hematocrit (\%) & $38.08 \pm 4.7$ \\
\hline Mean corpuscular volume (fL) & $81.86 \pm 5.75$ \\
\hline Mean corpuscular hemoglobin (pg) & $28.73 \pm 2.48$ \\
\hline Mean corpuscular hemoglobin concentration (g/dL) & $35.08 \pm 1.60$ \\
\hline Red cell distribution width (fL) & $14.80 \pm 1.97$ \\
\hline Platelets $\left(\times 10^{3} / \mu \mathrm{L}\right)$ & $202.03 \pm 82.51$ \\
\hline Lymph count $\left(10^{9}\right.$ cells/L) & $1214.80 \pm 875.5$ \\
\hline C-reactive protein (mg/L) & $84.31 \pm 61.65$ \\
\hline Neutrophil to lymphocyte ratio & $5.61 \pm 4.49$ \\
\hline Platelet to lymphocyte ratio & $202.8 \pm 124.93$ \\
\hline Lactate dehydrogenase (U/L) & $673.92 \pm 399.48$ \\
\hline Erythrocyte sedimentation rate $(\mathrm{mm} / \mathrm{h})$ & $60.17 \pm 31.31$ \\
\hline
\end{tabular}

were female. However, the male to female ratio was 1:1 in the non-lymphopenia group while it was found that the rate of lymphopenia was significantly higher in males $(P<0.05)$. The findings also revealed that developing lymphopenia was not significantly associated with diabetes, ischemic heart disease (IHD), hypertension (HTN), radiological evidence, death, need for hospitalization in the ICU, smoking, and antibiotic consumption $(P>0.05)$.

Investigation of the relationship between hematological indicators and radiological disease severity using radiological evidence showed no significant difference between the mean hematological and laboratory indicators of COVID-19 patients with lower or more than three lobes involvement $(P>0.05$; Table 4$)$.

The results of examining the relationship between platelet to lymphocyte ratio (PLR) and neutrophil to lymphocyte ratio (NLR) with regard to the disease severity 
Table 2. Hematological and laboratory indicators of COVID-19 patients at the time of admission and discharge

\begin{tabular}{|c|c|c|c|}
\hline Variable & Admission time $(n=95)$ & Discharge time $(n=94)$ & $P$ value \\
\hline White blood cells $\left(\times 10^{3} / \mu \mathrm{L}\right)$ & $7.27 \pm 3.48$ & $8.52 \pm 4.34$ & $0.001 *$ \\
\hline Red blood cells $\left(\times 10^{6} / \mu \mathrm{L}\right)$ & $4.66 \pm 0.65$ & $4.39 \pm 0.65$ & $<0.001^{*}$ \\
\hline Hemoglobin (g/dL) & $13.39 \pm 1.9$ & $12.43 \pm 1.9$ & $<0.001^{*}$ \\
\hline Hematocrit (\%) & $38.08 \pm 4.7$ & $36.76 \pm 5.04$ & $<0.001 *$ \\
\hline Mean corpuscular volume $(\mathrm{fL})$ & $81.86 \pm 5.75$ & $84.03 \pm 6.28$ & $<0.001^{*}$ \\
\hline Mean corpuscular hemoglobin (pg) & $28.73 \pm 2.48$ & $28.40 \pm 2.66$ & $0.001^{*}$ \\
\hline Mean corpuscular hemoglobin concentration (g/dL) & $35.08 \pm 1.60$ & $33.70 \pm 1.56$ & $<0.001^{*}$ \\
\hline Red cell distribution width (fL) & $14.80 \pm 1.97$ & $14.66 \pm 1.77$ & $0.001^{* *}$ \\
\hline Platelets $\left(\times 10^{3} / \mu \mathrm{L}\right)$ & $202.03 \pm 82.51$ & $268.58 \pm 137.34$ & $<0.001^{*}$ \\
\hline Lymph count $\left(10^{9}\right.$ cells/L) & $1214.80 \pm 875.5$ & $1376.85 \pm 717.2$ & $0.007^{*}$ \\
\hline
\end{tabular}

*Paired $t$ test; ${ }^{* *}$ Wilcoxon test.

Table 3. Frequency distribution of lymphopenia and non-lymphopenia cases regarding the disease risk factors

\begin{tabular}{|c|c|c|c|c|}
\hline Variable & & Lymphopenia (n=95) & Non-lymphopenia $(n=94)$ & $P$ value \\
\hline \multirow{2}{*}{ Age group (years) } & $<60$ & $47(49.5 \%)$ & $52(55.3 \%)$ & \multirow{2}{*}{0.421} \\
\hline & $\geq 60$ & $48(50.5 \%)$ & $42(44.7 \%)$ & \\
\hline \multirow{2}{*}{ Gender } & Male & $64(67.4 \%)$ & $47(50 \%)$ & \multirow{2}{*}{$0.015^{*}$} \\
\hline & Female & $31(32.6 \%)$ & $47(50 \%)$ & \\
\hline \multirow{2}{*}{ Diabetes } & Affected & $31(32.6 \%)$ & $29(30.9 \%)$ & \multirow{2}{*}{0.793} \\
\hline & Unaffected & $64(67.4 \%)$ & $65(69.1 \%)$ & \\
\hline \multirow{2}{*}{ Ischemic heart disease } & Affected & $16(16.8 \%)$ & $15(16 \%)$ & \multirow{2}{*}{0.870} \\
\hline & Unaffected & $79(83.2 \%)$ & $79(84 \%)$ & \\
\hline \multirow{2}{*}{ Hypertension } & Affected & $30(31.6 \%)$ & $24(25.5 \%)$ & \multirow{2}{*}{0.358} \\
\hline & Unaffected & $65(68.4 \%)$ & $70(74.5 \%)$ & \\
\hline \multirow{2}{*}{ Radiologic severity } & $2 \leq$ lobes & $31(32.6 \%)$ & $23(24.5 \%)$ & \multirow{2}{*}{0.214} \\
\hline & $3 \geq$ Lobes & $64(67.4 \%)$ & $71(75.5 \%)$ & \\
\hline \multirow{2}{*}{ Death } & Yes & $9(9.5 \%)$ & $11(11.7 \%)$ & \multirow{2}{*}{0.619} \\
\hline & No & $86(90.5 \%)$ & $83(88.3 \%)$ & \\
\hline \multirow{2}{*}{ Need for ICU } & Yes & $4(4.2 \%)$ & $9(9.6 \%)$ & \multirow{2}{*}{0.145} \\
\hline & No & $91(95.8 \%)$ & $85(90.4)$ & \\
\hline \multirow{2}{*}{ Smoking } & Yes & $81(85.3 \%)$ & $81(86.2 \%)$ & \multirow{2}{*}{0.859} \\
\hline & No & $14(14.7 \%)$ & $13(13.8 \%)$ & \\
\hline \multirow{2}{*}{ Olfactory sense } & Yes & $4(4.2 \%)$ & $13(13.8 \%)$ & \multirow{2}{*}{$0.021 *$} \\
\hline & No & $91(95.8 \%)$ & $81(86.2 \%)$ & \\
\hline \multirow{2}{*}{ Antibiotic consumption } & Ceftriaxone/azithromycin & $52(54.7 \%)$ & $60(63.8 \%)$ & \multirow{2}{*}{0.203} \\
\hline & Meropenem/vancomycin & $43(45.3 \%)$ & $34(36.2 \%)$ & \\
\hline \multirow{2}{*}{$\begin{array}{l}\text { Lymphopenia at } \\
\text { discharge }\end{array}$} & With lymphopenia & $46(82.14 \%)$ & $27(36 \%)$ & \multirow{2}{*}{0.009} \\
\hline & Without lymphopenia & $10(17.86 \%)$ & $48(64 \%)$ & \\
\hline \multirow{2}{*}{ Severity of the disease } & Moderate & $20(21.3 \%)$ & $12(12.8 \%)$ & \multirow{2}{*}{0.121} \\
\hline & Severe & $74(78.7 \%)$ & $82(87.2 \%)$ & \\
\hline
\end{tabular}

* Statically significant, ICU: intensive care unit.

showed no significant difference between PLR and NLR values $(P>0.05)$. Moreover, it was found that the mortality rate was significantly higher in patients with severe disease $(P=0.032$; Table 5). There was also no significant relationship between hospital length of stay and PLR $(P>0.05$; Table 6).

Investigation of the relationship between the subjects' PLR values and the need for hospitalization in the ICU clearly showed that the patients who needed to be hospitalized in the ICU had a higher PLR than others, which was statistically significant $(P<0.05)$. As shown in this table, NLR in those with more than seven days of hospital stay is significantly greater than those with $<7$ days (Table 6).

Figure 1 shows the ROC representation of laryngopharyngeal reflux values upon ICU admission. The ROC analysis demonstrated good performance with an AUC of 0.7 (95\% CI: 0.531-0.879, $P=0.01$; Figure 1). 
Table 4. Hematological and laboratory indicators of COVID-19 patients regarding the radiological disease severity

\begin{tabular}{|c|c|c|c|}
\hline \multirow{2}{*}{ Variable } & \multicolumn{2}{|c|}{ Radiological evidence } & \multirow{2}{*}{$P$ value } \\
\hline & $\geq 3$ Lobes & $\leq 2$ Lobes & \\
\hline White blood cells $\left(\times 10^{3} / \mu \mathrm{L}\right)$ & $7.26 \pm 3.30$ & $7.56 \pm 3.93$ & 0.598 \\
\hline Red blood cells $\left(\times 10^{6} / \mu \mathrm{L}\right)$ & $4.65 \pm 0.67$ & $4.73 \pm 0.65$ & 0.443 \\
\hline Hemoglobin $(\mathrm{g} / \mathrm{dL})$ & $13.30 \pm 1.91$ & $13.67 \pm 2.25$ & 0.241 \\
\hline Hematocrit $(\%)$ & $37.74 \pm 4.63$ & $39.03 \pm 5.65$ & 0.104 \\
\hline Mean corpuscular volume(fL) & $81.18 \pm 6.49$ & $82.44 \pm 4.08$ & 0.185 \\
\hline Mean corpuscular hemoglobin & $28.61 \pm 2.63$ & $28.81 \pm 1.94$ & 0.611 \\
\hline Mean corpuscular hemoglobin concentration (g/dL) & $34.99 \pm 2.28$ & $34.97 \pm 1.69$ & 0.964 \\
\hline Red cell distribution width (fL) & $14.83 \pm 1.97$ & $14.72 \pm 1.98$ & 0.728 \\
\hline Platelets $\left(\times 10^{3} / \mu \mathrm{L}\right)$ & $208.89 \pm 82.76$ & $194.87 \pm 73.09$ & 0.271 \\
\hline Lymph count $\left(10^{9} \mathrm{cells} / \mathrm{L}\right)$ & $1280.47 \pm 849.76$ & $1096.65 \pm 455.76$ & 0.520 \\
\hline C-reactive protein (mg/L) & $102.23 \pm 93.62$ & $73.01 \pm 61.31$ & 0.798 \\
\hline Erythrocyte sedimentation rate $(\mathrm{mm} / \mathrm{h})$ & $61.98 \pm 30.81$ & $54.88 \pm 32.61$ & 0.086 \\
\hline Neutrophil to lymphocyte ratio & $5.35 \pm 4.67$ & $6.22 \pm 4.03$ & 0.155 \\
\hline Platelet to lymphocyte ratio & $200.65 \pm 130.62$ & $208.15 \pm 110.38$ & 0.305 \\
\hline
\end{tabular}

As summarized in Table 7, investigating the correlation of erythrocyte sedimentation rate (ESR), lactate dehydrogenase, and C-reactive protein (CRP) with the PLR and NLR indicators showed a positive and significant correlation between ESR and PLR ( $\mathrm{r}=0.281, P<0.01)$. There was also a positive and significant correlation

Table 5. Relationship between clinical disease severity and platelet to lymphocyte ratio, neutrophil to lymphocyte ratio, and death in COVID-19 patients

\begin{tabular}{llll}
\hline \multirow{2}{*}{ Variable } & \multicolumn{2}{l}{ Severity of the disease } & \multirow{2}{*}{$\boldsymbol{P}$ value } \\
\cline { 2 - 3 } & $\begin{array}{l}\text { Moderate } \\
(\mathbf{n}=\mathbf{3 0})\end{array}$ & $\begin{array}{l}\text { Severe } \\
(\mathbf{n}=\mathbf{1 4 0})\end{array}$ & \\
\hline $\begin{array}{l}\text { Neutrophil to } \\
\text { lymphocyte ratio }\end{array}$ & $5.25 \pm 3.54$ & $5.69 \pm 4.68$ & $0.612^{\mathrm{a}}$ \\
$\begin{array}{l}\text { Platelet to lymphocyte } \\
\text { ratio }\end{array}$ & $203.79 \pm 95.22$ & $202.79 \pm 130.81$ & $0.967^{\mathrm{b}}$ \\
\begin{tabular}{l} 
Death \\
\multicolumn{1}{|l}{$\begin{array}{l}\text { With death } \\
\text { Without death }\end{array}$}
\end{tabular} & $0(0 \%)$ & $20(12.8 \%)$ & $0.032^{*}$ \\
\hline
\end{tabular}

* Statistically significant; Mann-Whitney test; ${ }^{\mathrm{b}}$ independent sample $t$ test.

Table 6. Relationship of the length of hospital stay and hospitalization in the intensive care unit with the platelet to lymphocyte ratio and neutrophil to lymphocyte ratio in COVID-19 patients

\begin{tabular}{lcc}
\hline Variables & $\begin{array}{c}\text { Neutrophil to } \\
\text { lymphocyte ratio }\end{array}$ & $\begin{array}{c}\text { Platelet to lymphocyte } \\
\text { ratio }\end{array}$ \\
\hline ICU admission & & \\
\hline Need for ICU admission & $8.95 \pm 11.34$ & $164.76 \pm 179.64$ \\
No need for ICU admission & $5.38 \pm 3.55$ & $205.6 \pm 120.16$ \\
$P$ value & 0.664 & $0.014^{*}$ \\
Length of hospital stay & & \\
$\geq 7$ days & $4.88 \pm 4.49$ & $183 \pm 98.9$ \\
$<7$ days & $6.4 \pm 4.46$ & $222.72 \pm 141.97$ \\
$P$ value & 0.003 & $0.099^{a}$ \\
\hline
\end{tabular}

ICU: intensive care unit.

* Statistically significant, ${ }^{\text {a }}$ Mann-Whitney test. between the patients' CRP and NLR $(r=0.317, P<0.01)$.

\section{Discussion}

Human coronavirus is one of the most important infectious pathogens of the respiratory system. According to the findings of previous studies, most of the COVID-19 patients have mild symptoms and a good prognosis, while only a small number of them have severe symptoms, including pneumonia, pulmonary edema, ARDS, the involvement of other organs like kidneys, liver, and nervous system, and death $(10,17)$.

The present study aimed to investigate the relationship between hematological parameters and disease severity in COVID-19 patients and the results revealed that the mean hematological and clinical indicators of the COVID-19 patients underwent significant changes. In other words, the patients' WBC, MCV, PLT, and lymph count had remarkably increased at the time of hospital discharge, while their red blood cells, $\mathrm{Hb}, \mathrm{HCT}, \mathrm{MCH}, \mathrm{MCHC}$, and

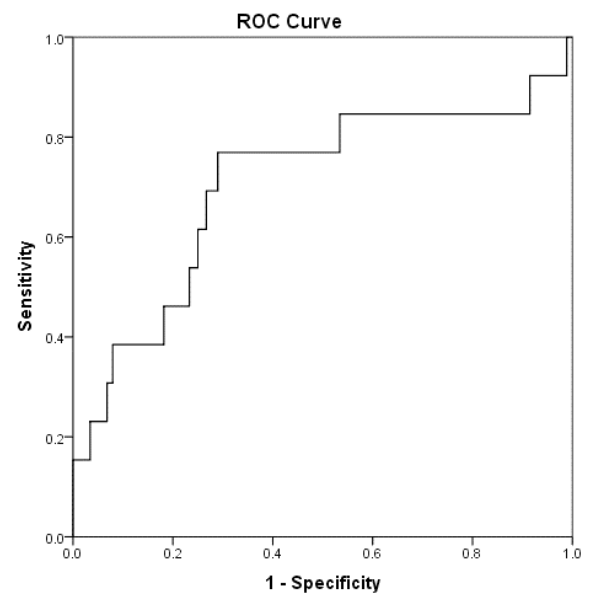

Figure 1. Area under the receiver operating curve in the assessment of lymphocyte to platelet ratio and hospitalization in the intensive care unit (area under the curve: 0.7 ). 
Table 7. Correlation between hematological indicators and the patients' PLR and neutrophil to lymphocyte ratio

\begin{tabular}{lll}
\hline Variable & Platelet to lymphocyte ratio & Neutrophil to lymphocyte ratio \\
\hline Erythrocyte sedimentation rate $(\mathrm{mm} / \mathrm{h})$ & $\mathrm{r}=0.281, P=0.001 *$ & $\mathrm{r}=0.176, P=0.064$ \\
Lactate dehydrogenase $(\mathrm{U} / \mathrm{L})$ & $\mathrm{r}=-0.185, P=0.137$ & $\mathrm{r}=0.202, P=0.121$ \\
C-reactive protein $(\mathrm{mg} / \mathrm{L})$ & $\mathrm{r}=0.116, P=0.194$ & $\mathrm{r}=0.317, P=0.001 *$ \\
\hline * Statistically significant & &
\end{tabular}

* Statistically significant.

RDW had significantly decreased by that time.

Regarding the disease severity, $83 \%$ of the studied patients were severe cases. The case fatality rate of COVID-19 in Iran has been reported at 6\%, while in our study it was found to be $10.6 \%$. This might be due to the more severity of the disease in the studied patients as $83 \%$ of them were in the severe stages of the disease.

Moreover, the results of the present study showed that gender and olfactory sense had a significant relationship with the development of lymphopenia associated with COVID-19. Accordingly, male subjects and those lacking olfactory sense had a higher percentage of lymphopenia in the present study which is in line with the results of previous researches (18-20). Regarding co-morbidities, $31.7 \%, 16.4 \%$, and $28.6 \%$ of the patients suffered from diabetes, cardiovascular diseases, and HTN, respectively which is consistent with the results of other studies. However, no significant relationship was found between co-morbidities and disease severity. In their study, Yang et al (21) found that about $21.1 \%, 9.7 \%$, and $8.4 \%$ of the patients had HTN, diabetes, and cardiovascular diseases, respectively.

According to the studies conducted on COVID-19 patients, hematological indicators and parameters were altered by the coronavirus. Lippi et al (22) clearly showed that PLT levels were significantly lower in severe cases and that low PLTs would lead to a fivefold increase in the risk of disease severity. Furthermore, the fatality rate of COVID-19 was significantly higher in patients with lower PLT, compared to others.

Our findings also indicated that PLR was significantly lower in patients who were admitted to the ICU, compared to those who were not admitted to the ICU. Besides, the amount of NLR had a significant relationship with the length of hospital stay. Accordingly, patients with high NLR were hospitalized for an average of more than seven days.

Henry et al in their study about the hematological parameters of COVID-19 patients (23) suggested that the more severe and deadly cases of the disease had higher WBC count and lower lymphocyte and PLT than the mild cases. In their study, CRP had also increased as an indicator of systemic inflammation in COVID-19 patients. In this regard, routine evaluation of hematological parameters, including PLR and NLR, is suggested as a prognostic predictor of COVID-19 patients (24).

\section{Conclusion}

According to the results, hematological parameters and inflammatory biomarkers in the COVID-19 patients potentially act as independent factors and affect the disease prognosis. Hence, conducting further studies with the risk stratification approach may help identify the factors that contribute to the early diagnosis of the patients and administration of adjuvant therapies.

\section{Limitations of the study}

The low number of patients may be a limitation for this study. Thus designing a larger study with more participants suggests.

\section{Acknowledgments}

The researchers would like to express their gratitude to the Research Deputy of Mashhad University of Medical Sciences and all the hospital staff for their contribution to the implementation of this research project. The authors would also like to thank the Clinical Research Development Unit of Ghaem Hospital for their cooperation in data analysis.

\section{Authors' contribution}

MSS designed the study. ZRB wrote the manuscript. SNM and MM were included in preparing the concept and design. $\mathrm{AA}, \mathrm{NS}, \mathrm{FE}$, ZJA, SK, MAR, SR, MN, ZM, MMN, HR, AB, MK, SAA and MAY revisited the manuscript and critically evaluated the intellectual contents. ME analyzed the data. All authors participated in preparing the final draft of the manuscript, revised the manuscript and critically evaluated the intellectual contents. All authors have read and approved the content of the manuscript and confirmed the accuracy or integrity of any part of the work.

\section{Conflicts of interest}

The authors declare that they have no competing interests.

\section{Ethical considerations}

Ethical issues (including plagiarism, data fabrication, double publication) have been completely observed by the authors.

\section{Funding/Support}

This study was funded by Mashhad University of Medical Sciences (Grant\#99/14214).

\section{References}

1. de Groot RJ, Baker SC, Baric RS, Brown CS, Drosten C, Enjuanes L, et al. Commentary: Middle East respiratory syndrome coronavirus (MERS-CoV): announcement of the Coronavirus Study Group. J Virol. 2013;87:7790-2. doi: 10.1128/JVI.01244-13.

2. Gao GF. From "A" IV to "Z" IKV: attacks from emerging and reemerging pathogens. Cell. 2018;172:1157-9. doi: 10.1016/j. cell.2018.02.025.

3. Ksiazek TG, Erdman D, Goldsmith CS, Zaki SR, Peret T, Emery 
S, et al. A novel coronavirus associated with severe acute respiratory syndrome. N Engl J Med. 2003;348:1953-66. doi: 10.1056/NEJMoa030781.

4. Kuiken T, Fouchier RA, Schutten M, Rimmelzwaan GF, Van Amerongen G, van Riel D, et al. Newly discovered coronavirus as the primary cause of severe acute respiratory syndrome. The Lancet. 2003;362:263-70. doi: 10.1016/ S0140-6736(03)13967-0.

5. World Health Organization. Middle East respiratory syndrome coronavirus (MERS-CoV). November, 2019. Available from: https://www.who.int/emergencies/mers-cov/en/.

6. World Health Organization. Summary of probable SARS cases with onset of illness from 1 November 2002 to 31 July 2003. http://www.who.int/csr/sars/country/table2004_04_21/en/ index html. 2003.

7. Weiss SR, Leibowitz JL. Coronavirus pathogenesis. In: Advances in Virus Research. Elsevier; 2011. p. 85-164. doi: 10.1016/B978-0-12-385885-6.00009-2.

8. Zhu N, Zhang D, Wang W, Li X, Yang B, Song J, et al. A novel coronavirus from patients with pneumonia in China, 2019. N Engl J Med. 2020. doi: 10.1056/NEJMoa2001017.

9. Chen N, Zhou M, Dong X, Qu J, Gong F, Han Y, et al. Epidemiological and clinical characteristics of 99 cases of 2019 novel coronavirus pneumonia in Wuhan, China: a descriptive study. Lancet. 2020;395:507-13. doi: 10.1016/ S0140-6736(20)30211-7.

10. Huang C, Wang Y, Li X, Ren L, Zhao J, Hu Y, et al. Clinical features of patients infected with 2019 novel coronavirus in Wuhan, China. Lancet. 2020;395:497-506. doi: 10.1016/ S0140-6736(20)30183-5.

11. Lei S, Jiang F, Su W, Chen C, Chen J, Mei W, et al. Clinical characteristics and outcomes of patients undergoing surgeries during the incubation period of COVID-19 infection. EClinicalMedicine. 2020;21:100331. doi: 10.1016/j. eclinm.2020.100331.

12. Yang A-P, Liu J, Tao W, Li H-m. The diagnostic and predictive role of NLR, d-NLR and PLR in COVID-19 patients. Int Immunopharmacol. 2020;84:106504. doi: 10.1016/j. intimp.2020.106504.

13. Holshue ML, DeBolt C, Lindquist S, Lofy KH, Wiesman J, Bruce $\mathrm{H}$, et al. First case of 2019 novel coronavirus in the United States. N Engl J Med. 2020. doi: 10.1056/NEJMoa2001191.

14. Silverstein WK, Stroud L, Cleghorn GE, Leis JA. First imported case of 2019 novel coronavirus in Canada, presenting as mild pneumonia. Lancet. 2020;395:734 .doi: 10.1016/S01406736(20)30370-6.

15. Wang D, Hu B, Hu C, Zhu F, Liu X, Zhang J, et al. Clinical characteristics of 138 hospitalized patients with 2019 novel coronavirus-infected pneumonia in Wuhan, China. JAMA. 2020. doi:10.1001/jama.2020.1585.

16. Guan WJ, Ni ZY, Hu Y, Liang WH, Ou CQ, He JX, et al. Clinical characteristics of coronavirus disease 2019 in China. N Engl J Med. 2020;382:1708-20. doi: 10.1056/NEJMoa2002032

17. Yin Y, Wunderink RG. MERS, SARS and other coronaviruses as causes of pneumonia. Respirology. 2018;23:130-7. doi: 10.1111/resp.13196.

18. Dowd JB, Andriano L, Brazel DM, Rotondi V, Block P, Ding X, et al. Demographic science aids in understanding the spread and fatality rates of COVID-19. Proc Natl Acad Sci U S A. 2020. doi: 10.1101/2020.03.15.20036293.

19. Hjelmesæth J, Skaare D. Loss of smell or taste as the only symptom of COVID-19. Tidsskr Nor Laegeforen. 2020. doi: 10.4045/tidsskr.20.0287.

20. Hopkins C, Kumar N. Loss of sense of smell as marker of COVID-19 infection. Available from: https://www.entuk. org/sites/default/files/files/Loss\%20of\%20sense\%20of\%20 smell\%20as\%20marker\%20of\%20COVID.pdf.

21. Yang J, Zheng Y, Gou X, Pu K, Chen Z, Guo Q, et al. Prevalence of comorbidities in the novel Wuhan coronavirus (COVID-19) infection: a systematic review and meta-analysis. Int J Infect Dis. 2020. doi: 10.1016/j.ijid.2020.03.017.

22. Lippi G, Plebani M, Henry BM. Thrombocytopenia is associated with severe coronavirus disease 2019 (COVID-19) infections :A meta-analysis. Clin Chim Acta. 2020. doi: 10.1016/j.cca.2020.03.022.

23. Clinical Chemistry and Laboratory Medicine (CCLM)Henry BM, de Oliveira MHS, Benoit S, Plebani M, Lippi G. Hematologic, biochemical and immune biomarker abnormalities associated with severe illness and mortality in coronavirus disease 2019 (COVID-19): a meta-analysis. Clin Chem Lab Med. 2020 Jun 25:58:1021-8. doi: 10.1515/cclm-2020-0369.

24. Zhou F, Yu T, Du R, Fan G, Liu Y, Liu Z, et al. Clinical course and risk factors for mortality of adult inpatients with COVID-19 in Wuhan, China: a retrospective cohort study. Lancet. 2020. doi: 10.1016/S0140-6736(20)30566-3. 